\title{
Electrochemical detection of cholesterol in a buffer solution with a glassy carbon electrode doctored by ZnO/SnO2/RuO2 nanomaterials
}

Md Mahmud Alam ( $\sim$ alam-mahmud@hotmail.com )

Shahjalal University of Science and Technology https://orcid.org/0000-0002-2636-5038

M.T. Uddin

Shahjalal University of Science and Technology

Abdullah M. Asiri

King Abdulaziz University

Mohammed M. Rahman

King Abdulaziz University

M.A. Islam

Shahjalal University of Science and Technology

\section{Research Article}

Keywords: $\mathrm{ZnO} / \mathrm{SnO} 2 / \mathrm{RuO} 2$ nanoparticles, Cholesterol sensor, Pathological diagnosis, Electrochemical method, Glassy carbon electrode

Posted Date: February 16th, 2021

DOI: https://doi.org/10.21203/rs.3.rs-227092/v1

License: (c) (i) This work is licensed under a Creative Commons Attribution 4.0 International License. Read Full License 


\section{Abstract}

This electrochemical study performed to develop a cholesterol sensor using a glassy carbon electrode (GCE) coating with ternary low-dimensional $\mathrm{ZnO} / \mathrm{SnO}_{2} / \mathrm{RuO}_{2}$ nanomaterials ( $\mathrm{NMs}$ ). The $\mathrm{ZnO} / \mathrm{SnO}_{2} / \mathrm{RuO}_{2}$ NMs characterized using FESEM, XPS, EDS and XRD analysis. The desired cholesterol sensor fabricated by coating a GCE with $\mathrm{ZnO} / \mathrm{SnO}_{2} / \mathrm{RuO}_{2} \mathrm{NMs}$ as a film of the thin-layer using suspension of ethanol with $5 \%$ Nafion binder, which performed to the analysis of cholesterol electrochemically in the phosphate buffer phase. The resulted electrochemical responses have exhibited the linearity from $0.1 \mathrm{nM} \sim 0.01 \mathrm{mM}$ of cholesterol in current versus concentration plot, which defined as a calibration curve of this sensor development. The linear concentration $(0.1 \mathrm{nM} \sim 0.01 \mathrm{mM})$ of cholesterol corresponding with the current response is known as the dynamic range (LDR) for detection of target analyte. The sensitivity is calculated from the slope of calibration-curve found as $11.3513 \mu \mathrm{AMM}^{-1} \mathrm{~cm}^{-2}$. The lower limit of detection $(91.42 \pm 4.57 \mathrm{pM})$ is obtained from signal/noise $(\mathrm{S} / \mathrm{N}=3)$ at 3 . In the real-samples detection process, the fabricated cholesterol sensor is exhibited good reproducibility, fast response time and ability to perform in long-duration of sensor elapse time. In the end, this method is shown the reliable detection of cholesterol in the buffer phase and would be very perspective in the recent future in-term of a simple as well as reliable technique in the field of pathological diagnosis.

\section{Introduction:}

The cholesterol is a steroid wax of fat and essential element of the cell membrane in mammalian. It performs a precursor to the formation of varies biochemical such as steroid hormones, vitamin $D$, and bile acid [1, 2]. The cholesterol concentration in blood is a fundamental indicator of the detection of numerous diseases as coronary heart disease, hypertension, lipid metabolism dysfunction, brain thrombosis, arteriosclerosis, and myocardial infarction [3-5]. Therefore, imbalanced cholesterol in human blood (low and high) is responsible for human health hazardous effects [6-9]. Herein, a sensitive and reliable method to detect cholesterol is necessary. Up to date, the spectrometric [10], colourimetric [11] and electrochemical methods [12] are applying for this purpose. An alternative approach of the electrochemical technique is a popular topic to researchers due to its reliable detection of numerous biochemical using metal oxides (semi-conductive) on GCE [13-16]. Therefore, this study performed to fabricate a sensor by a mixture of semi-conductor metal oxides coating a GCE.

The $\mathrm{ZnO}$ p-type semiconductor has $3.37 \mathrm{eV}$ bandgap energy, and $60 \mathrm{meV}$ exciting binding energy. As a result, it exhibits the attractive photosensitivity, electrochemical properties, and stability, essential for the fabrication of reliable biochemical sensor [17-18]. Several types of research have shown ZnO as successive sensing mediator for the detection of benzaldehyde [20], bisphenol A [21], acetone [22], ethanol [23] and melamine sensor [24] and others. The SnO2 is another semi-conductive metal oxide having bandgap energy of $3.6 \mathrm{eV}$, and due to the useful physio-electro-chemical properties, it has widely applied as a catalyst, biosensor, lithium battery, gas sensor and monitoring electronic device for environmental monitoring [25-29]. The transition metal oxide is RuO2 containing the favourable the electrochemical properties for technological application. For its the high stability (chemical), and 
conductivity with excellent diffusion barrier properties, the Various application of RuO2 have been executed such as supercapacitors, the electrode of chlorine generator, catalyst for splitting the water, $\mathrm{CO} 2$ methanation and $\mathrm{CO}$ sensor $[30,31]$.

Therefore, the objective of this study is to the development of a biochemical sensor applying $\mathrm{ZnO} / \mathrm{SnO}_{2} / \mathrm{RuO}_{2} \mathrm{NMs}$ as a thin film on GCE using $5 \%$ Nafion suspension as a binder to the selective detection cholesterol in the buffer phase. From the linear relation of current versus concentration of cholesterol, the analytical parameters of cholesterol sensor calculated. Furthermore, the fabricated cholesterol admired in the analysis of real bio-samples. Thus, this is a unique technique for the development of future sensor technology in pathological diagnosis.

\section{Experimental:}

\section{Materials and methodology:}

The nanoparticles of $\mathrm{ZnO} / \mathrm{SnO}_{2} / \mathrm{RuO}_{2}$ prepared to apply wet-chemical synthesis method using the analytical grade of $\mathrm{Zn}\left(\mathrm{CH}_{3} \mathrm{COO}\right)_{2} \cdot 2 \mathrm{H}_{2} \mathrm{O}, \mathrm{SnCl}_{4}$, ruthenium(III)2,4-pentanedionate and urea as precursors obtained from Sigma-Aldrich. Moreover, D-glucose, uric acid, folic acid, L-leucine, bilirubin, testosterone, Llactic acid, choline, tannic acid and cholesterol in the form of analytical grade were procured from the Sigma-Aldrich and supporting chemicals such as mono- \& disodium phosphate and $5 \%$ Nafion in ethanol was used to execute this study. The Thermo-scientific XPS with K-a1 radiation source, $300.0 \mu \mathrm{m}$ beam and $200.0 \mathrm{eV}$ pass energy performing at 10-8Torr implemented to investigate the ionization states of the existing atoms ( $\mathrm{Ru}, \mathrm{O}, \mathrm{Sn}$ and $\mathrm{Zn}$ ). The morphology of the prepared NMs figured out by FSEM (JEOL, JSM-7600F, Japan) attached to EDS analysis. The unit cell crystallinity and grain size of NMs evaluated by the powder X-ray diffraction analysis. The electrochemical characterization of $\mathrm{ZnO} / \mathrm{SnO} 2 / \mathrm{RuO} 2 \mathrm{NMs}$ on GCE examined through a Keithley electrometer as the source of a constant supply of potential (volts).

The synthesized of $\mathrm{ZnO} / \mathrm{SnO}_{2} / \mathrm{RuO}_{2} \mathrm{NMs}$ :

$\mathrm{ZnO} / \mathrm{SnO}_{2} / \mathrm{RuO}_{2}$ nanoparticles prepared by homogenous precipitation technique, where, zinc acetate dihydrate $\left(\mathrm{Zn}\left(\mathrm{CH}_{3} \mathrm{COO}\right)_{2} \cdot 2 \mathrm{H}_{2} \mathrm{O}\right)$ and tin tetrachloride used as precursors, and urea as a precipitating agent. In a typical procedure, the $5 \mathrm{~mL}$ of $\mathrm{SnCl} 4$ and $20 \mathrm{~g}$ of urea added in $100 \mathrm{~mL}$ water (deionized) into a $200 \mathrm{~mL}$ beaker. The solution stirred with a magnetic bar at $90^{\circ} \mathrm{C}$ for four hours with reflux. At these high alkaline conditions, the white precipitates obtained. Then, it centrifuged to separate from the aqueous reaction medium and successively washed with deionized water to till neutral. At $110^{\circ} \mathrm{C}$, the resultant white precipitate dried overnight in an oven, and after that, it crashed into a mortar to make nano-sized particles. Subsequently, the nano-powder calcined into a muffle furnace at $500^{\circ} \mathrm{C}$ in the presence of atmospheric air for 5 hours to obtain $\mathrm{SnO}_{2}$ nanoparticle. A similar procedure applied to prepare $\mathrm{ZnO}$ nanoparticle. At this procedure, $3.12 \mathrm{~g} \mathrm{Zn}\left(\mathrm{CH}_{3} \mathrm{COO}\right)_{2}$. $2 \mathrm{H} 2 \mathrm{O}$ dissolved in $200 \mathrm{~mL}$ of water (deionized) with $12 \mathrm{~g}$ of urea into $300 \mathrm{~mL}$ beaker and stirred until homogeneous mixture obtained. Then, it followed keeping at $90^{\circ} \mathrm{C}$ around 4 hours on the heating plat to precipitate out quantitatively. After the 
separation and washing with deionized water successively of resultant precipitate mass, it dried at $110^{\circ} \mathrm{C}$ overnight. Then, the calcination carried out into muffle furnace at the same procedure as in above. To form $10 \%$ of ruthenium in a mixture $\left(10 \% \mathrm{RuO}_{2}, 45 \% \mathrm{SnO}_{2}\right.$ and $\left.45 \% \mathrm{ZnO}\right)$, the calculated amount of ruthenium (III) 2, 4-pentanedionate dispersed into $50 \mathrm{~mL}$ deionized water with $\mathrm{SnO}_{2}$ and $\mathrm{ZnO}$ in $100 \mathrm{~mL}$ beaker following by stirring at room conditions. Then, water removed by drying in an oven at $110^{\circ} \mathrm{C}$ overnight. The obtained powder was then ground and calcined at $500{ }^{\circ} \mathrm{C}$ for two hours in the air to achieve the desired $\mathrm{ZnO} / \mathrm{SnO}_{2} / \mathrm{RuO}_{2} \mathrm{NMs}$.

The fabrication of GCE by $\mathrm{ZnO} / \mathrm{SnO}_{2} / \mathrm{RuO}_{2} \mathrm{NMs}$ :

The working electrode is the heart of an electrochemical sensor, and it assembled by the modification of GCE with prepared $\mathrm{ZnO} / \mathrm{SnO}_{2} / \mathrm{RuO}_{2} \mathrm{NMs}$. In this typical fabrication method, a thick ethanolic slurry of synthesized $\mathrm{ZnO} / \mathrm{SnO}_{2} / \mathrm{RuO}_{2} \mathrm{NMs}$ prepared, and applied to layer on a GCE as a thin film very carefully. Subsequently, it dried at the room conditions. For the necessary stability of NMs layer on GCE, few drops of Nafion added on the dry modified surface of GCE and followed keeping at $35^{\circ} \mathrm{C}$ into an oven for a satisfying duration to dry it again. The sensor assembling using Keithley electrometer did, where $\mathrm{ZnO} / \mathrm{SnO}_{2} / \mathrm{RuO}_{2} \mathrm{NMs} / \mathrm{GCE}$ and Pt-wire connected at electrometer in a series manner performing as working and counter electrode respectively. The mother solution of cholesterol $(0.1 \mathrm{mM})$ used to prepare several solutions ranging from $0.1 \mathrm{mM}$ to $0.1 \mathrm{nM}$ acting as a targeted analyte in I-V analysis. The sensors parameters sensitivity, LDR, and DL calculated from the slope, obtained from a linear plot of current versus concentration of cholesterol named calibration curve. The buffer solutions formed by the equimolar mixing of mono- \& disodium phosphate in deionized water. In the I-V investigation, the buffer solution took $10 \mathrm{~mL}$ in the measurement as constant through the experiment. The sensor applying electrochemical (I-V) approach is a simple two-electrode system (working and counter).

\section{Results And Discussions:}

\section{The surface composition analysis by XPS:}

The binding energy (eV) and ionizations of NMs analyzed by the XPS investigation. The resultant data presented at Fig. 1 showing the orbitals of Zn2p level located at 1022 and $1045 \mathrm{eV}$ with the respect of $Z n 2 p_{3 / 2}$ and $Z n 2 p_{1 / 2}$ spin orbitals separately. The $Z n 2 p$ level's spin orbitals separate with $23 \mathrm{eV}$, a characteristic value of $\mathrm{Zn}^{2+}$ oxidation, which has been reported previously [32-34]. The 01s orbital shows an XPS peak located at $531 \mathrm{eV}$ and can recognize as chemisorbed oxygen on NMs surface involved the oxidation of $\mathrm{O}^{2}$ [35-37]. The orbitals of Sn3d level recognized as the spin orbitals of $\mathrm{Sn} \mathrm{d}_{5 / 2}$ and $\mathrm{Sn}_{3} \mathrm{~d}_{3 / 2}$ are shown in Fig. 1(c) and positioned at 487 and $495 \mathrm{eV}$ correspondingly with the binding energy separation of $8 \mathrm{eV}$, which is conformed $\mathrm{Sn}^{4+}$ oxidation in the synthesized $\mathrm{ZnO} / \mathrm{SnO}_{2} / \mathrm{RuO}_{2} \mathrm{NMs}$ [38-40]. XPS peak of Ru3d shows two recognized orbitals (spin) located at 281.08 and $285.12 \mathrm{eV}$, which are corresponded to Ru3d $d_{5 / 2}$ and Ru3d $d_{3 / 2}$ spin orbitals shown in Fig. $1(d)$, but the spin-orbital of Ru3d $d_{3 / 2}$ 
overlapped with C1s orbital. The spin energy difference between Ru3d $d_{5 / 2}$ and Ru3d $d_{3 / 2}$ is equal to $4.04 \mathrm{eV}$ a characteristic value of $\mathrm{Ru}^{4+}$ ionized state $[41,42]$.

\section{The morphology of synthesized $\mathrm{ZnO} / \mathrm{SnO}_{2} / \mathrm{RuO}_{2} \mathrm{NMs}$ :}

The FESEM analysis performed to evaluate the structural morphology as-prepared $\mathrm{ZnO} / \mathrm{SnO} 2 / \mathrm{RuO} 2 \mathrm{NMs}$ exemplified in Fig. 2(a-b) showing the low and high magnifying images of prepared nanomaterials. As seemed at Fig. 1(a-b), the prepared nanomaterials consist of grains of distinct shapes and sizes. The similar information's explores in EDS report as in Fig. 2(c), and it confirmes that the synthesized NMs have contained various shape and sizes containing Zn, O, Sn and Ru only shown in Fig. 2(d). The weight compositions of nanomaterials are Zn $43.29 \%$, Sn $48.99 \%$, $01.26 \%$ and Ru $8.97 \%$.

\section{Powdered X-ray diffraction pattern of $\mathrm{ZnO} / \mathrm{SnO}_{2} / \mathrm{RuO}_{2} \mathrm{NMs}$ :}

To assess, the grains crystallinity and size of $\mathrm{ZnO} / \mathrm{SnO} 2 / \mathrm{RuO} 2 \mathrm{NMs}$ evaluate by $\mathrm{XRD}$ analysis performed at $2 \theta$ degree $\left(20 \sim 80^{\circ}\right.$ range) shown in Fig.3, and the resultant XRD data confirmes the existence of the crystalline phases of ZnO, SnO2 and RuO2 only. The crystalline peaks of SnO2 are (110), (201), (220), (310), (301) and (321) perceive in Fig. 3, and identified by JCPDS no. 0045-0937 and previously reported articles on SnO2 [43,44]. Besides this, the diffracted peaks associated with ZnO such as (002), (101), (200) and (202) verified by JCDS no. 0036-1451 and prior authors illustrated in Fig. 3 [45,46]. Moreover, the trace RuO2 shows two pecks associated with plans of (211) and (220) as explored in Fig. 3 and identified by reported articles $[47,48]$. The average crystal size $\mathrm{ZnO} / \mathrm{SnO} / \mathrm{RuO} 2 \mathrm{NMs}$ estimates following the Scherrer Equation.

$D=(0.94 \lambda) /(\beta \operatorname{Cos} \theta)$

Herein $\lambda$ (wavelength of X-ray radiation) and $\beta$ (the width at half of peak). The calculated crystal size of synthesized NRs is $7.75 \mathrm{~nm}$ at $\mathrm{SnO}_{2}(110)$.

\section{The cholesterol detection with $\mathrm{ZnO} / \mathrm{SnO}_{2} / \mathrm{RuO}_{2} \mathrm{NMs}$ sensor:}

The sensor selective to cholesterol amassed with wet-chemically prepared $\mathrm{ZnO} / \mathrm{SnO}_{2} / \mathrm{RuO}_{2} \mathrm{NMs}$ layered on GCE as a film. The GCE modified by the slurry of $\mathrm{ZnO} / \mathrm{SnO}_{2} / \mathrm{RuO}_{2} \mathrm{NMs}$ in ethanol, and the coating did as an efficient way to form a layer of NMs film. The stability of NMs film on GCE enhanced by adding a few drops of Nafion, which improved it's the working duration in buffer solution. The Nafion is known as conductive co-polymer. Therefore, the use of Nafion in the working electrode is enhanced the electron transfer rate of the sensor. As a result, the sensor shows high I-V performances, in the buffer phase, in the cholesterol analyze. The observations like this have reported detecting chemicals and biochemical [4953]. It appears $\mathrm{ZnO} / \mathrm{SnO}_{2} / \mathrm{RuO}_{2} \mathrm{NMs}$ first time onto GCE to analyze cholesterol and any report regarding this not available. The sensor in the I-V technique is a two-electrode system (working and counter electrode). In the electrochemical investigation of cholesterol in the buffer phase, the holding time in Keithley electrometer set as $1 \mathrm{~s}$. 
Initially, the fabricated sensor based on $\mathrm{ZnO} / \mathrm{SnO}_{2} / \mathrm{RuO}_{2} \mathrm{NMs} / \mathrm{GCE}$ was applied to investigate several biochemical including D-glucose, uric acid, folic acid, L-leucine, bilirubin, testosterone, L-lactic acid, choline, tannic acid and cholesterol and achieved data presented in Fig. 4(a). The experimented results show in Fig. 4(a), which did at $0.1 \mu \mathrm{M}$ of each biochemical and applied volts ranging from 0 to $+1.5 \mathrm{~V}$ in the buffer phase of pH 7.0. It explores in Fig. 4(a) that cholesterol exhibits the uppermost current against the applied potential $(\mathrm{V}$ ) and on a comparison of the highest I-V outcome, the cholesterol identifies as selective for the sensor with $\mathrm{ZnO} / \mathrm{SnO}_{2} / \mathrm{RuO}_{2} \mathrm{NMs} / \mathrm{GCE}$. Then, the selected cholesterol subjected to analyze in a rage of concentration of $0.1 \mathrm{nM} 0.1 \mathrm{mM}$ in buffer system of $\mathrm{pH} 7.0$ as exemplified in Fig. 4(b). From the explored I-V curve in Fig. 4(b), it is found that the I-V responses of cholesterol increased with increasing of cholesterol concentration from lower to higher and the resulted I-V outcomes are completely a parted from each other in the sequence of lower-higher concentration of cholesterol. Thus, as shown, the I-V plots are varied with the corresponding concentration of cholesterol as a similar observation has described by earlier authors [54-59].

As illustrated in Fig. 4(c) current versus concentration of cholesterol plot is known as calibration of cholesterol biosensor, and it shows the linearity of current density on a line with corresponding potential (volt) from $0.1 \mathrm{nM}$ to $0.01 \mathrm{mM}$ of cholesterol, which identified a dynamic range (LDR) to measure. The obtained LDR is consist of a wide range of concentration. To identify the linearity of LDR, current versus $\log$ (conc.) was plotted, which matched with the regression coefficient $(\mathrm{R} 2=0.9901)$ and provided evidence of the linearity of LDR. The sensor sensitivity is an important parameter and calculated from the slope of calibration-curve divided by the cross-section of GCE $(0.0316 \mathrm{~cm} 2)$, and exceptional sensitivity of $11.3513 \mu \mathrm{A} \mu \mathrm{M}-1 \mathrm{~cm}-2$ is apparent. The lower limit of the sensor is calculated by applying $3(\mathrm{~S} / \mathrm{N})$ as the signal-noise ratio and found as $91.42 \pm 4.57 \mathrm{pM}$, which might be appreciable.

The response time measures the sensor efficiency, which defines as the minimum time required to complete the I-V analysis of an analyte. The cholesterol sensor's response time executed by the plotting of current versus time shown in Fig. 5(a). As perceived in Fig. 5(a), the currents versus time relation become steady at around $20 \mathrm{~s}$. Therefore, it can conclude that the proposed sensor can complete I-V analysis within $20 \mathrm{~s}$ and provides the evidence of high efficiency of cholesterol sensor with $\mathrm{ZnO} / \mathrm{SnO}_{2} / \mathrm{RuO}_{2} \mathrm{NMs} / \mathrm{GCE}$. As known, the prepared nanomaterials are a doped mixture of $\mathrm{ZnO}, \mathrm{SnO}_{2}$ and $\mathrm{RuO}_{2}$. Thus, the I- $\mathrm{V}$ activities of single, binary and ternary metal oxides compared in the detection of cholesterol in the buffer phase and illustrated in Fig. 5(b). As it is exemplified in Fig. 5(b), the doped $\mathrm{ZnO} / \mathrm{SnO}_{2} / \mathrm{RuO}_{2} \mathrm{NMs}$ exhibited the highest electrochemical response, and it is due to the combinational effect of ternary compositions. The reproducibility measures the reliability of a sensor and is an ability to generate identical I-V responses in the analysis of an analyte. For the reliability, the sensor subjected to I-V analysis of cholesterol in the similar conditions such as $0.1 \mu \mathrm{M}$ concentration, potential range $0 \sim+1.5 \mathrm{~V}$ in the buffer of pH 7.0 in the continuous seven hours and the outcomes demonstrated in Fig. 5(c). The I-V responses do not change after washing of the electrode in each analysis. The precision of currents data measure at applied potential $+1.5 \mathrm{~V}$ in term of relative standard deviation (RSD), and the outcome is $0.55 \%$ (RSD), which is to confirm the high precision. A similar method, the longtime performing ability of 
sensor tested as shown in Fig. 5(d) at a similar condition as in reproducibility test. The outcomes are analogous with the reproducibility. Thus, the projected cholesterol sensor with $\mathrm{ZnO} / \mathrm{SnO}_{2} / \mathrm{RuO}_{2} \mathrm{NMs} / \mathrm{GCE}$ is well enough to analyze the cholesterol in real bio-samples in electrochemical approach.

A proposed scheme for cholesterol electrochemical oxidation is presented below. The molecules of cholesterol are adsorbed on $\mathrm{ZnO} / \mathrm{SnO}$ /RuO2 NMs/GCE surface and oxidized to cholesta-4,6-dien-3-one. In this oxidation of cholesterol, few electrons are formed, which enhances the conductivity buffer solution. As result, the enhanced I-V responses record in the Keithley electrometer. The cholesterol oxidation like similar has described previously $[60,61]$.

The contrast of similar studies are demonstrated in Table 1 in term of the analytical performances of sensor such as LDR, sensitivity and DL [62-64]. Based on the parameters, the cholesterol sensor with $\mathrm{ZnO} / \mathrm{SnO}_{2} / \mathrm{RuO}_{2} \mathrm{NMs} / \mathrm{GCE}$ shows the appreciable performances.

Table 1: The contract of the similar studies in term of analytical parameters of cholesterol sensor with $\mathrm{ZnO} / \mathrm{SnO}_{2} / \mathrm{RuO}_{2} \mathrm{NMs} / \mathrm{GCE}$.

\begin{tabular}{|c|c|c|c|c|}
\hline Modified GCE & LDR & Sensitivity & DL & Ref. \\
\hline $\begin{array}{l}\mathrm{ChEt}-\mathrm{ChO} \text { / } / \mathrm{MWCNT} / \mathrm{SiO}_{2}-\mathrm{CHIT} / \mathrm{ITO} \\
\text { /GCE }\end{array}$ & $10 \sim 500 \mu M$ & $\begin{array}{l}3.8^{*} 10^{-3} \\
\mu A \mu M^{-1} \mathrm{~cm}^{-2}\end{array}$ & -- & 62 \\
\hline Ti/NPAu/ChOx-HRP-ChE/GCE & - - & $\begin{array}{l}2.93^{*} 10^{-2} \\
\mu A \mu M^{-1} \mathrm{~cm}^{-2}\end{array}$ & - & 63 \\
\hline ZnO NRs/GCE & $0.001 \sim 45 \mathrm{mM}$ & $\begin{array}{l}10^{*} 10^{-3} \\
\mu A \mu M^{-1} \mathrm{~cm}^{-2}\end{array}$ & - & 64 \\
\hline $\mathrm{ZnO} / \mathrm{SnO}_{2} / \mathrm{RuO}_{2} \mathrm{NMs} / G C E$ & $0.1 \mathrm{nM} \sim 0.01 \mathrm{mM}$ & $\begin{array}{l}11.3513 \\
\mu A \mu M^{-1} \mathrm{~cm}^{-2}\end{array}$ & $\begin{array}{l}91.42 \\
p M\end{array}$ & $\begin{array}{l}\text { This } \\
\text { work }\end{array}$ \\
\hline
\end{tabular}

${ }^{*} D L$ (detection limit), LDR (linear dynamic range), $p M($ picomole), $m M($ millimole).

\section{The analysis of bio-samples applying recovery method:}

To appropriate the validation of cholesterol sensor with $\mathrm{ZnO} / \mathrm{SnO}_{2} / \mathrm{RuO}_{2} \mathrm{NMs} / \mathrm{GCE}$ assembly, the biosamples such as human, mouse and rabbit serums were collected and analyzed by I-V approach. The resulted data are presented in the Table 2 and it seemed to quit satisfactory.

Table 2: The analysis of real environmental samples using $\mathrm{ZnO} / \mathrm{SnO}_{2} / \mathrm{RuO}_{2} \mathrm{NMs} / \mathrm{GCE}$ chemical sensor by recovery method. 


\begin{tabular}{|c|c|c|c|c|c|c|}
\hline \multirow[t]{2}{*}{ Sample } & \multirow[t]{2}{*}{$\begin{array}{l}\text { Added cholesterol } \\
\text { conc. }(\mu \mathrm{M})\end{array}$} & \multicolumn{3}{|c|}{$\begin{array}{l}\text { Measured cholesterol conc. }{ }^{\mathrm{a}} \text { by } \\
\mathrm{ZnO} / \mathrm{SnO}_{2} / \mathrm{RuO}_{2} \mathrm{NMs} / \mathrm{GCE}(\mu \mathrm{M})\end{array}$} & \multirow[t]{2}{*}{$\begin{array}{l}\text { Average } \\
\text { recovery }^{\mathrm{b}}(\%)\end{array}$} & \multirow{2}{*}{$\begin{array}{l}\mathrm{RSD}^{\mathrm{c}} \\
(\%) \\
(\mathrm{n}=3)\end{array}$} \\
\hline & & $\mathrm{R} 1$ & $\mathrm{R} 2$ & R3 & & \\
\hline $\begin{array}{l}\text { Human } \\
\text { serum }\end{array}$ & 0.01000 & 0.01026 & 0.01022 & 0.01013 & 102.03 & 0.65 \\
\hline $\begin{array}{l}\text { Mouse } \\
\text { serum }\end{array}$ & 0.01000 & 0.01044 & 0.01047 & 0.01031 & 104.06 & 0.82 \\
\hline $\begin{array}{l}\text { Rabbit } \\
\text { serum }\end{array}$ & 0.01000 & 0.01012 & 0.01004 & 0.01000 & 100.56 & 0.61 \\
\hline
\end{tabular}

${ }^{a}$ Mean of three repeated determination (signal to noise ratio 3) $\mathrm{ZnO} / \mathrm{SnO}_{2} / \mathrm{RuO}_{2} \mathrm{NMs} / \mathrm{GCE}$.

${ }^{b}$ Concentration of cholesterol determined/Concentration taken. (Unit: $\left.\mu \mathrm{M}\right)$

${ }^{c}$ Relative standard deviation value indicates precision among three repeated measurements $(R 1, R 2, R 3)$.

\section{Conclusion:}

Here, the wet-chemically prepared $\mathrm{ZnO} / \mathrm{SnO}_{2} / \mathrm{RuO}_{2} \mathrm{NMs}$ were totally characterized by using FESEM, XRD, EDS and XPS. The cholesterol sensor with $\mathrm{ZnO} / \mathrm{SnO}_{2} / \mathrm{RuO}_{2} \mathrm{NMs} / \mathrm{GCE}$ was subjected to analysis of cholesterol in phosphate buffer phase to evaluate the sensor analytical parameters such as reproducibility, stability, response time, sensitivity, LDR and DL and found as satisfactory. To validate this sensor, it was applied to detect cholesterol in real bio-samples by recovery method and showed the acceptable results. Thus, this technique for the development of electrochemical sensor to analyze the biochemicals would be a prospective approach in the field of pathological diagnosis in a broad scale.

\section{References}

1. J.I. Cleeman, C. Lenfant. The National Cholesterol Education Program. Progress and prospects, J. Am. Med. Assoc. 280 (1998) 2099-2104.

2. A.I. Gopalan, K.P. Lee, D. Ragupathy. Development of a stable cholesterol biosensor based on multiwalled carbon nanotubes-gold nanoparticles composite covered with a layer of chitosan-roomtemperature ionic liquid network. Biosens. Bioelectron. 24 (2009) 2211-2217.

3. T. Nakaminami, S. Ito, S. Kuwabata, H. Yoneyama. Amperometric determination of total cholesterol at gold electrodes covalently modified with cholesterol oxidase and cholesterol esterase with use of thionin as an electron mediator. Anal. Chem. 71 (1999) 1068-1076.

4. A. Mondal, N.R. Jana. Fluorescent detection of cholesterol using beta-cyclodextrin functionalized graphene. Chem. Commun. 48 (2012)7316-7318. 
5. R. Li, C. Xiong, Z. Xiao, L. Ling. Colorimetric detection of cholesterol with G-quadruplex-based DNAzymes and ABTS2. Anal. Chim. Acta. 724 (2012)80-85.

6. H.G. Li, M.H. El-Dakdouki, D.C. Zhu, G.S. Abela, X.F. Huang. Synthesis of $\beta$-yclodextrin conjugated superparamagnetic iron oxide nanoparticles for selective binding and detection of cholesterol crystals. Chem. Commun. 48(2012) 3385-3387.

7. V. Raj, R. Jaime, D. Astruc, K. Sreenivasan. Detection of cholesterol by digitonin conjugated gold nanoparticles. Biosens. Bioelectron. 27 (2011) 197-200.

8. S.R. Cao, L. Zhang, Y.Q. Chai, R. Yuan. An integrated sensing system for detection of cholesterol based on $\mathrm{TiO}_{2}$-graphene-Pt-Pd hybrid nanocomposites, Biosens. Bioelectron. 42 (2013) 532-538.

9. N. Zhang, Y.Y. Liu, L.L. Tong, K.H. Xu, L.H. Zhuo, B. Tang. A novel assembly of Au NPs-b-CDs-FL for the fluorescent probing of cholesterol and its application in blood serum. Analyst 133 (2008) 11761181.

10. T. Nakaminami, S. Kuwabata, H. Yoneyama. Electrochemical oxidation of cholesterol catalyzed by cholesterol oxidase with use of an artificial electron mediator. Anal. Chem. 69 (1997) 2367-2372.

11. A. Krug, R. Gobel, R. Kellner. Flow-injection analysis for total cholesterol with photometric detection. Anal. Chim. Acta. 287 (1994) 59-64.

12. W. Trettnak, I. Lionti, M. Mascini. Cholesterol biosensors prepared by electro-polymerization of pyrrole, Electroanalysis. 5 (1993) 753-763.

13. M.M. Rahman, M.M. Alam, A.M. Asiri. Detection of toxic choline based on $\mathrm{Mn}_{2} \mathrm{O}_{3}$ /NiOnanomaterials by an electrochemical method. RSC Adv. 9 (2019) 35146-35157.

14. M.M. Alam, A.M. Asiri, M.T. Uddin, M.A. Islam, M.R. Awual, M.M. Rahman. Detection of uric acid based on doped $\mathrm{ZnO} / \mathrm{Ag}_{2} \mathrm{O} / \mathrm{Co}_{3} \mathrm{O}_{4}$ nanoparticle loaded glassy carbon electrode. New J. Chem. 43 (2019) 8651-8659.

15. M.M. Alam, A.M. Asiri, M.T. Uddin, M.A. Islam, M.M. Rahman. In-situ Glycine Sensor Development Based $\mathrm{ZnO} / \mathrm{Al}_{2} \mathrm{O}_{3} / \mathrm{Cr}_{2} \mathrm{O}_{3}$ Nanoparticles. Chemistry Select. 3 (2018) 11460-11468.

16. M.M. Alam, A.M. Asiri, M.T. Uddin, M.A. Islam, M.M. Rahman. Wet-chemically prepared lowdimensional $\mathrm{ZnO} / \mathrm{Al}_{2} \mathrm{O}_{3} / \mathrm{Cr}_{2} \mathrm{O}_{3}$ nanoparticles for xanthine sensor development using an electrochemical method. RSC Adv. 8 (2018) 12562-12572.

17. K.S Lee, C.W. Park, J.D. Kim. Electrochemical properties and characterization of various ZnO structures using a precipitation method. Colloids and Surfaces A: Physicochem. Eng. Aspects. 512 (2017) 87-92.

18. M. Chakraborty, P. Mahapatra, R. Thangavel. Structural, optical and electrochemical properties of Al and $\mathrm{Cu}$ co-doped $\mathrm{ZnO}$ nanorods synthesized by a hydrothermal method. Thin Solid Films. 612 (2016) 49-54.

19. H. Zeng, Y. Cao, S. Xie, J. Yang, Z. Tang, X. Wang, L. Sun. Synthesis, optical and electrochemical properties of ZnO nanowires/graphene oxide heterostructures. Nanoscale Research Letters. 8 (2013) 133. 
20. M.M. Rahman, M.M. Alam, A.M. Asiri. Carbon black co-adsorbed ZnO nanocomposites for selective benzaldehyde sensor development by electrochemical approach for environmental safety. Journal of Industrial and Engineering Chemistry. 65 (2018) 300-308.

21. M.A. Subhan, P.C. Saha, M.M. Alam, A.M. Asiri, M. Al-Mamund, M.M. Rahman. Development of BisPhenol A sensor based on $\mathrm{Fe}_{2} \mathrm{MoO}_{4} \cdot \mathrm{Fe}_{3} \mathrm{O}_{4} \cdot \mathrm{ZnO}$ nanoparticles for sustainable environment. Journal of Environmental Chemical Engineering. 6 (2018) 1396-1403.

22. M.M. Rahman, M.M. Alam, A.M. Asiri, M.A. Islam. Fabrication of selective chemical sensor with ternary $\mathrm{ZnO} / \mathrm{SnO}_{2} / \mathrm{Yb}_{2} \mathrm{O}_{3}$ nanoparticles. Talanta. 170 (2017) 215-223.

23. M.M. Rahman, M.M. Alam, A.M. Asiri, M.A. Islam. Ethanol sensor development based on ternarydoped metal oxides ( $\mathrm{CdO} / \mathrm{ZnO} / \mathrm{Yb}_{2} \mathrm{O}_{3}$ ) nanosheetsfor environmental safety. RSC Adv. 7 (2017) 22627-22639.

24. M.M. Alam, A.M. Asiri, M.T. Uddin, Inamuddin, M.A. Islam, M.R. Awual, M.M. Rahman. One-step wetchemical synthesis of ternary $\mathrm{ZnO} / \mathrm{CuO} / \mathrm{Co}_{3} \mathrm{O}_{4}$ nanoparticles for sensitive and selective melamine sensor development. New J. Chem. 43 (2019) 4849-4858.

25. M.G. Thakare, C.G. Dighavkar, A.V. Borhade, J.S. Aher. Synthesis, Characterization and Application of $\mathrm{SnO}_{2}$ Nanoparticles. International Journal of Recent Trends in Engineering \& Research. 2 (2016) 2455-1457.

26. H. Liu, Sh. Gong, Y. Hu, J. Zhao, J. Liu, Zh. Zheng, D. Zhou. Tin oxide nanoparticles synthesized by gel combustion and their potential for gas detection. Ceram. Int. 35 (2009) 961-966.

27. X. Chu, Y. Han, S. Zhou, H. Shui. Trimethylamine sensing properties of nano- $\mathrm{SnO}_{2}$ prepared using microwave heating method. Ceram. Int. 36 (2010) 2175-2180.

28. Y. Tan, Ch. Li, Y. Wang, J. Tang, X. Ouyang. Fast-response and high sensitivity gas sensors based on $\mathrm{SnO}_{2}$ hollow spheres. Thin Solid Films. 516 (2008) 7840-7843.

29. E. R. Kötz, S. Stucki. Ruthenium dioxide as a hydrogen-evolving cathode. J. Appl. Electrochem. 17 (1987) 1190-1197.

30. A. Mills, P. A. Duckmanton, J. Reglinski. A simple, novel method for preparing an effective water oxidation catalyst, Chem. Commun. 46 (2010) 2397.

31. K. Reuter, M. Scheffler. Surface and Solution Mediated Studies of Small Molecule Enediyne Reactivity. Phys. Rev. B Condens. Matter Mater. Phys. 73 (2006) 045433/1-045433/17.

32. D. Xu, D. Fan. W. Shen. Catalyst-free direct vapor-phase growth of $\mathrm{Zn}_{1-\mathrm{x}} \mathrm{Cu}_{\mathrm{x}} \mathrm{O}$ micro-cross structures and their optical properties. Nanoscale Research Letters. 8 (2013) 46.

33. K. Vignesh, S. Kang, B.S. Kwak, M. Kang. Meso-porous ZnO nano-triangles @ graphitic- $\mathrm{C}_{3} \mathrm{~N}_{4}$ nanofoils: Fabrication and Recyclable photocatalytic activity. Separation and Purification Technology. 147 (2015) 257-265.

34. J. Zhang, D. Gao, G. Yang, J. Zhang, Z. Shi, Z. Zhang, Z. Zhu, D. Xue. Synthesis and magnetic properties of Zr doped ZnO Nanoparticles. Nanoscale Research Letters. 6 (2011) 587. 
35. S. Balachandran, S.G. Praveen, R. Velmurugan, M. Swaminathan. Facile fabrication of highly efficient, reusable heterostructured $\mathrm{Ag}-\mathrm{ZnO}-\mathrm{CdO}$ and its twin applications of dye degradation under natural sunlight and self-cleaning. RSC Adv. 4 (2014) 4353-4362.

36. B.T. Sone, M. Maaza. Room Temperature Green Synthesis of CdO Nanoparticles Using Aqueous Extracts of Callistemon Viminalis. J. Nanomater. Mol. Nanotechnol. 6 (2017) 1.

37. N. Lavanya, S. Radhakrishnan, N. Sudhan, C. Sekar, S.G. Leonardi, C. Cannilla, G. Neri. Fabrication of folic acid sensor based on the $\mathrm{Cu}$ doped $\mathrm{SnO}_{2}$ nanoparticles modified glassy carbon electrode. Nanotechnology. 25 (2014) 295501.

38. G. Singh, M. Kaur, B. Arora, R.C. Singh. Investigation of ethanol gas sensing properties of Dy-doped $\mathrm{SnO}_{2}$ nanostructures. J. Mater. Sci: Mater. Electron. 29 (2018) 867-875.

39. J. Liu, T. Wang, B. Wang, P. Sun, Q. Yang, X. Liang, H. Song, G. Lu. Highly sensitive and low detection limit of ethanol gas sensor based on hollow $\mathrm{ZnO} / \mathrm{SnO}_{2}$ spheres composite material. Sensors and Actuators B. 245 (2017) 551-559.

40. P. Wu, Y. Huang, L. Kang, M. Wu, Y. Wang. Multisource Synergistic Electrocatalytic Oxidation Effect of Strongly Coupled PdM (M = Sn, Pb)/N-doped Graphene Nanocomposite on Small Organic Molecules. Scientific Reports 5 (2015) 14173.

41. K.V. Egorov, Y. Yu, Lebedinskii, A.A. Soloviev, A.A. Chouprik, A. Yu, Azarov, A.M. Markeev. Initial and steady-state Ru growth by atomic layer deposition studied by in situ Angle Resolved X-ray Photoelectron Spectroscopy. Applied Surface Science. 419 (2017) 107-113.

42. A. Foelske, O. Barbieri, M. Hahn and R. Kotz. Electrochem. An X-ray photoelectron spectroscopy study of hydrous ruthenium oxide powders with various water contents for supercapacitors. Solid-State Lett. 9 (2006) A268-A272.

43. R.N. Mariammal, K. Ramachandrana, B. Renganathanb, D. Sastikumar. On the enhancement of ethanol sensing by $\mathrm{CuO}$ modified $\mathrm{SnO}_{2}$ nanoparticles using fiber-optic sensor. Sensors and Actuators B. 169 (2012) 199-207.

44. A. Debataraja, D.W. Zulhendri, B. Yuliarto, Nugraha, Hiskia, B. Sunendar. Investigation of Nanostructured $\mathrm{SnO}_{2}$ Synthesized with Polyol Technique for $\mathrm{CO}$ Gas Sensor Applications. Procedia Engineering. 170 (2017) $60-64$.

45. D. Raoufi. Synthesis and microstructural properties of $\mathrm{ZnO}$ nanoparticles prepared by precipitation method. Renewable Energy. 50 (2013) 932-937.

46. A.K. Zak, R. Razali, W.H.A. Majid, M. Darroudi. Synthesis and characterization of a narrow size distribution of zinc oxide nanoparticles. International Journal of Nanomedicine. 6 (2011) 13991403.

47. H. Lee, Y. Kim, A. Yu, D. Jin, A. Jo, Y. Lee, M.H. Kim, C. Lee. An Efficient Electrochemical Sensor Driven by Hierarchical Hetero-Nanostructures Consisting of RuO2 Nanorods on WO3 Nanofibers for Detecting Biologically Relevant Molecules. Sensors. 19 (2019) 3295. 
48. R. Thangappan, M. Arivanandhan, R.D. Kumar, R. Jayavel. Facile synthesis of RuO2 nanoparticles anchored on graphene nanosheets for high performance composite electrode for supercapacitor applications. Journal of Physics and Chemistry of Solids. 121 (2018) 339-349.

49. R.H. Rakib, M.A. Hasnat, M. N. Uddin, M.M. Alam, A.M. Asiri, M.M. Rahman, I.A. Siddiquey. Fabrication of a 3,4-Diaminotoluene Sensor Basedon a $\mathrm{TiO}_{2}-\mathrm{Al}_{2} \mathrm{O}_{3}$ Nanocomposite Synthesized by a Fast and Facile Microwave Irradiation Method. Chemistry Select. 4 (2019) 12592-12600.

50. M.M. Rahman, M.M. Alam, Detection of toxic choline based on $\mathrm{Mn}_{2} \mathrm{O}_{3} / \mathrm{NiO}$ nanomaterials by an electrochemical method. A.M. Asiri. RSC Adv. 9 (2019) 35146-35157.

51. M.M. Rahman, M.M. Alam, K.A. Alamry. Sensitive and selective $m$-tolyl hydrazine chemical sensor development based on CdO nanomaterial decorated multi-walled carbon nanotubes. Journal of Industrial and Engineering Chemistry. 77 (2019) 309-316.

52. M.M. Rahman, M.M. Alam, A.M. Asiri. Development of an efficient phenolic sensor based on facile $\mathrm{Ag}_{2} \mathrm{O} / \mathrm{Sb}_{2} \mathrm{O}_{3}$ nanoparticles for environmental safety. Nanoscale Adv. 1 (2019) 696-705.

53. M.R. Karim, M.M. Alam, M.O. Aijaz, A.M. Asiri, M.A. Dar, M.M. Rahman. Fabrication of 1,4-dioxane sensor based on microwave assisted $\mathrm{PAni}^{-S_{0} \mathrm{O}_{2}}$ nanocomposites. Talanta. 193 (2019) 64-69.

54. M.M. Rahman, A. Wahid, M.M. Alam, A.M. Asiri. Efficient 4-Nitrophenol sensor development based on facile $\mathrm{Ag} @ \mathrm{Nd}_{2} \mathrm{O}_{3}$ nanoparticles. Materials Today Communications. 16 (2018) 307-313.

55. M.M. Rahman, M.M. Alam, A.M. Asiri. Selective hydrazine sensor fabrication with facilelowdimensional $\mathrm{Fe}_{2} \mathrm{O}_{3} / \mathrm{CeO}_{2}$ nanocubes. New J. Chem. 42 (2018) 10263-10270.

56. M.M. Rahman, M.M. Alam, M.M. Hussain, A.M. Asiri, M.E.M. Zayed. Hydrothermally prepared $\mathrm{Ag}_{2} \mathrm{O} / \mathrm{CuO}$ nanomaterial for an efficient chemical sensor development for environmental remediation. Environmental Nanotechnology, Monitoring \& Management. 10 (2018) 1-9.

57. M.M. Rahman, M.M. Alam, A.M. Asiri. Sensitive 1,2-dichlorobenzene chemi-sensor development based onsolvothermally prepared $\mathrm{FeO} / \mathrm{CdO}$ nanocubes for environmental safety. Journal of Industrial and Engineering Chemistry. 62 (2018) 392-400.

58. M.M. Rahman, M.M. Alam, A.M. Asiri. 2-Nitrophenol sensor-based wet-chemically prepared binary doped $\mathrm{Co} 304 / \mathrm{Al}_{2} \mathrm{O}_{3}$ nanosheets by an electrochemical approach. RSC Adv. 8 (2018) 960-970.

59. M.M. Rahman, M.M. Alam, A.M. Asiri, M.A. Islam. 3,4-Diaminotoluene sensor development based on hydrothermally prepared $\mathrm{MnCo}_{x} \mathrm{O}_{y}$ nanoparticles. Talanta. 176 (2018) 17-25.

60. S. Singh, A. Chaubey, B.D. Malhotra. Amperometric cholesterol biosensor based on immobilized cholesterol esterase and cholesterol oxidase on conducting polypyrrole films. Analytica Chimica Acta. 502 (2004) 229-234.

61. Y.Y. Hosokawa, H. Hakamata, T. Murakamia, S. Aoyagi, M. Kuroda, Y. Mimaki, A. Ito, S. Morosawa, F. Kusu. Electrochemical oxidation of cholesterol in acetonitrile leads to the formation of cholesta-4,6dien-3-one. Electrochimica Acta. 54 (2009) 6412-6416.

62. P.R. Solanki, A. Kaushik, A.A. Ansari, A. Tiwari, B.D. Malhotra. Multi-walled carbon nanotubes/sol-gelderived silica/chitosan nanobiocomposite for total cholesterol sensor. Sensors and Actuators B. 137 
(2009) 727-735.

63. A. Ahmadalinezhad, A. Chen. High-performance electrochemical biosensor for the detection of total cholesterol. Biosensors and Bioelectronics. 26 (2011) 4508- 4513.

64. R. Ahmad, N. Tripathy, Y.B. Hahn. High-performance cholesterol sensor based on the solution-gated field effect transistor fabricated with ZnO nanorods. Biosensors and Bioelectronics. 45 (2013) 281286.

Figures
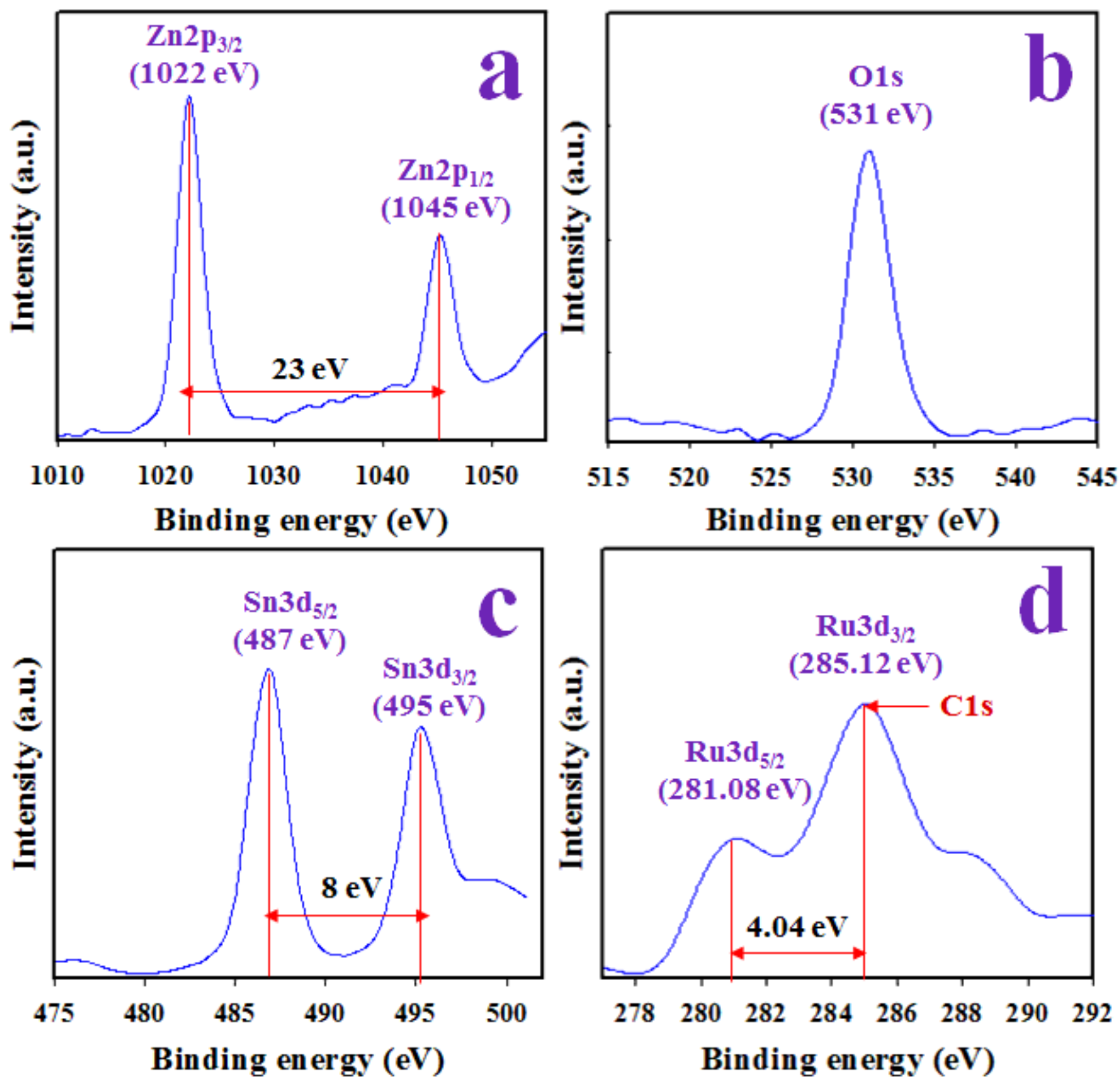

Figure 1 
The surface composition analysis by the implementation of XPS. (a) The core level spin orbitals of Zn2p level, (b) 01s orbit, (c) Sn3d level orbitals and (d) Ru3d orbits.
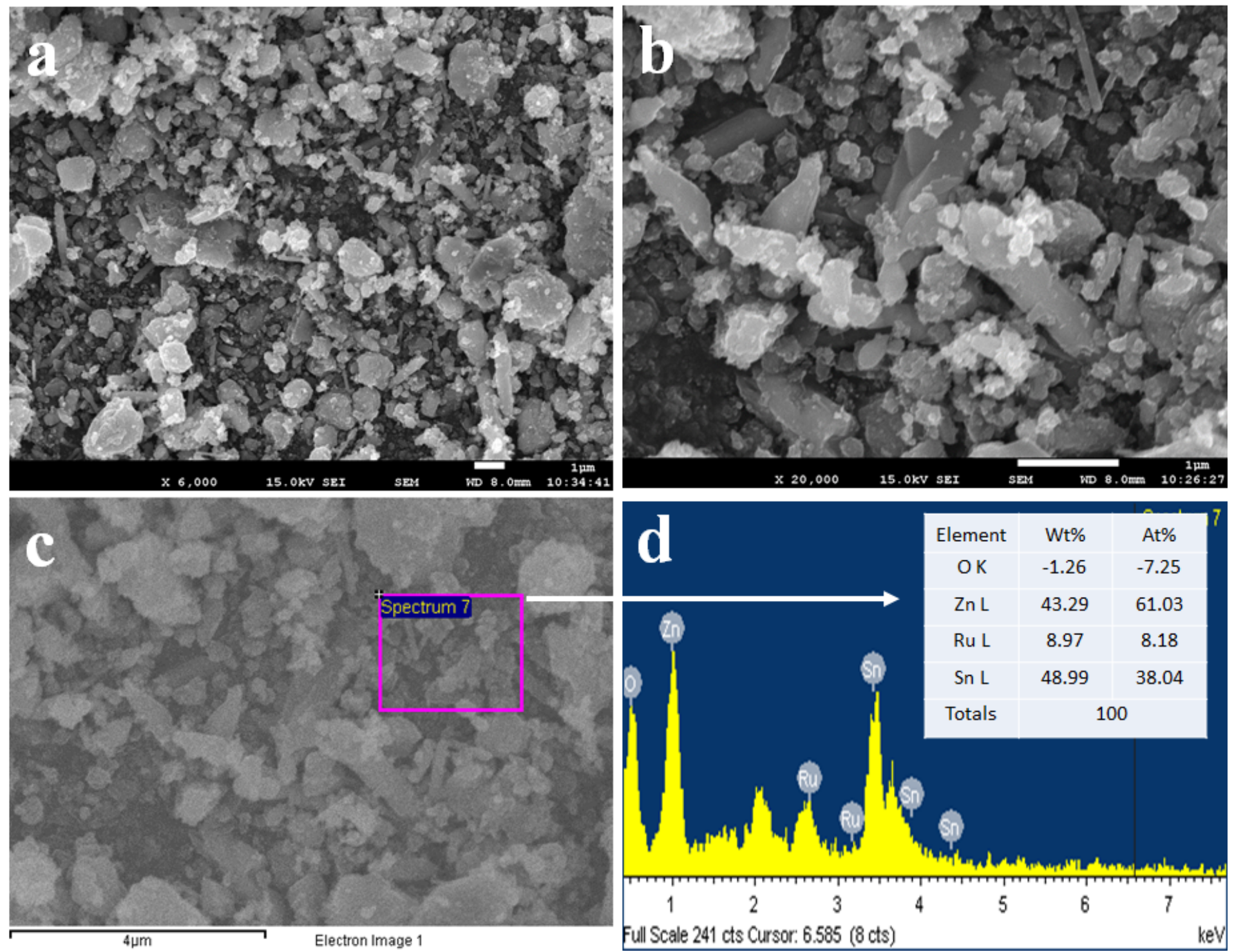

\section{Figure 2}

The morphology and elemental composition of $\mathrm{ZnO} / \mathrm{SnO} 2 / \mathrm{RuO}^{2} \mathrm{NMs}$ analyzed by ESEM and EDS. (a-b) The magnified images (low and high) of NMs executed by FESEM analysis, (c) EDS image $\mathrm{ZnO} / \mathrm{SnO} 2 / \mathrm{RuO} 2 \mathrm{NMs}$ and (d) atomic and weight percentage of the corresponding elements. 


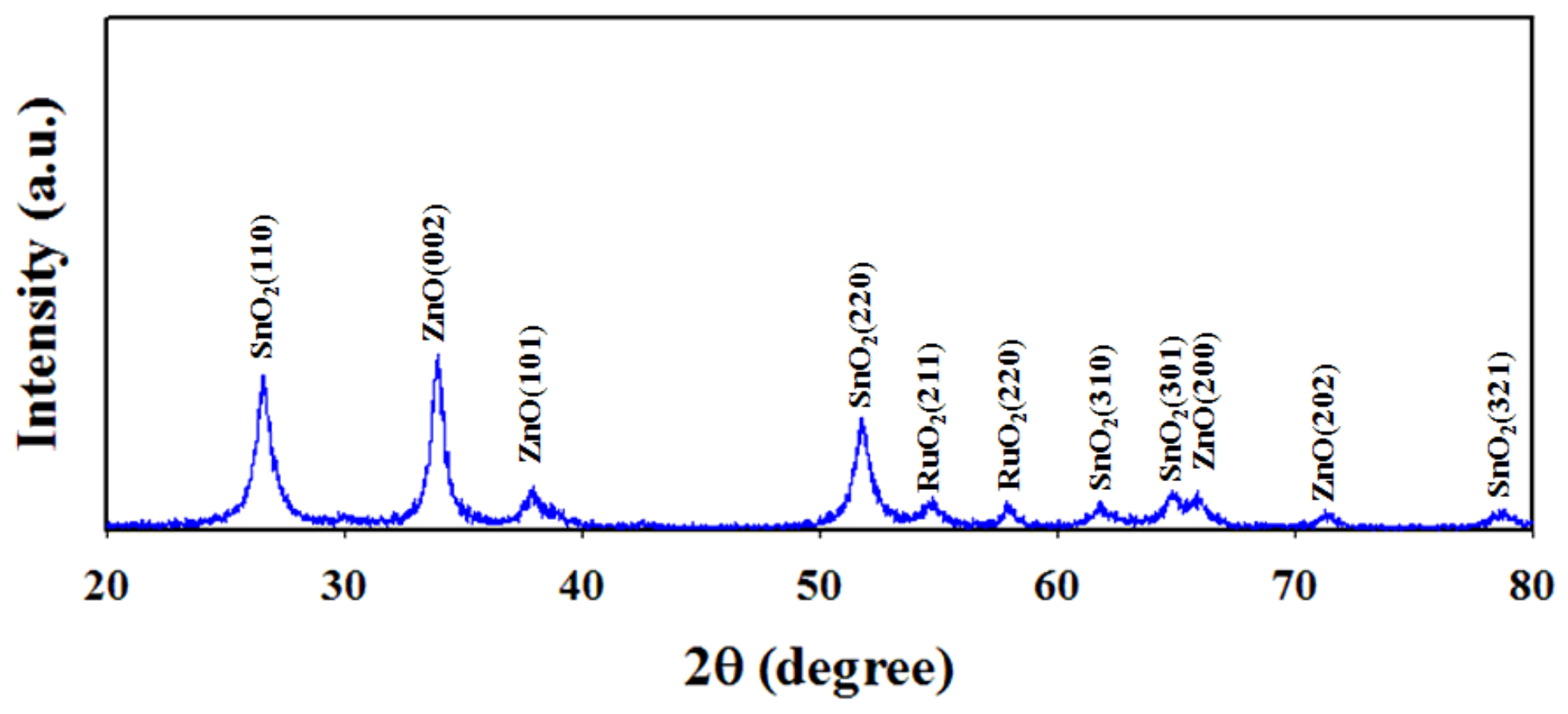

Figure 3

The X-ray diffraction pattern of $\mathrm{ZnO} / \mathrm{SnO} / \mathrm{RuO} 2 \mathrm{NMs}$. 

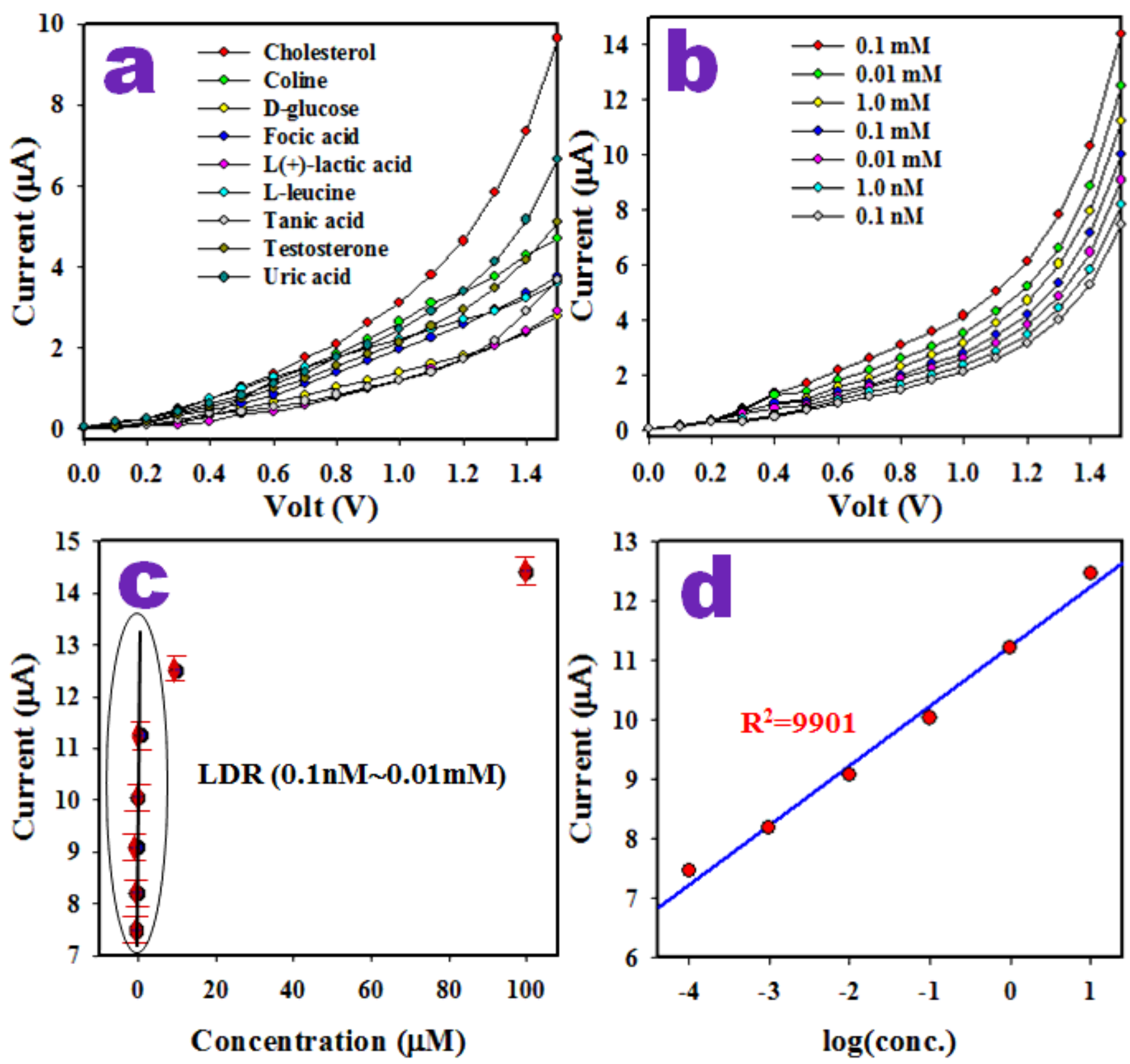

Figure 4

The electrochemical characterization of sensor with $\mathrm{ZnO} / \mathrm{SnO} 2 / \mathrm{RuO} 2 \mathrm{NMs} / \mathrm{GCE}$. (a) The identification of selectivity using $0.1 \mu \mathrm{M}$ of analytes in phosphate buffer, (b) I-V outcomes of cholesterol in range of concentration of $0.1 \mathrm{nM} \sim 0.1 \mathrm{mM}$, (c) calibration from current verses conc. curve and (d) current verses log (conc.) 

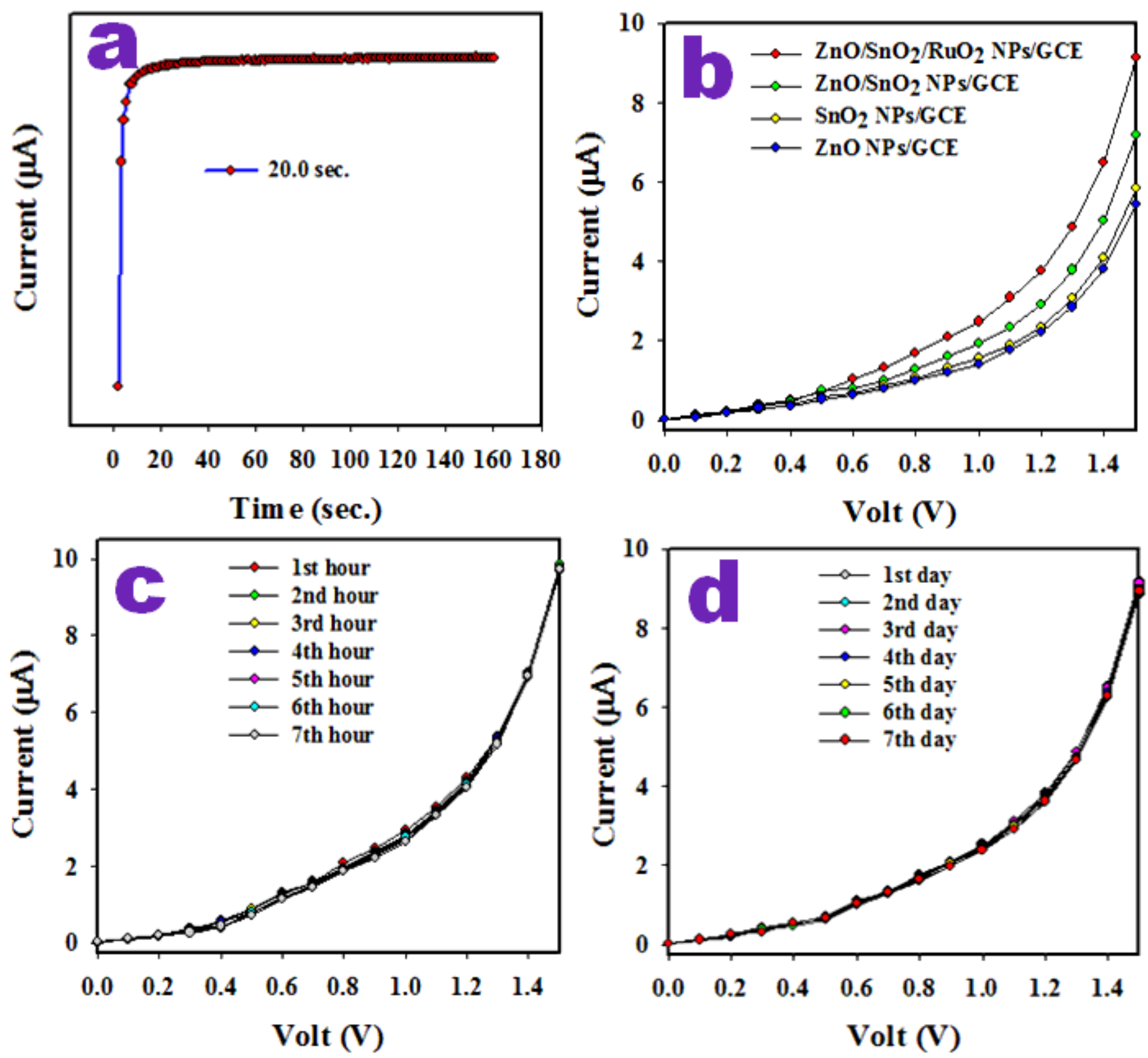

Figure 5

The investigation of the analytical parameters of cholesterol sensor based on $\mathrm{ZnO} / \mathrm{SnO} 2 / \mathrm{RuO} 2$ NMs/GCE. (a) Response time, (b) the I-V responses based on the GCE modified by various compositions, (c) reproducibility and (d) long-time performing capability.

\section{Supplementary Files}

This is a list of supplementary files associated with this preprint. Click to download.

- Scheme1.png 